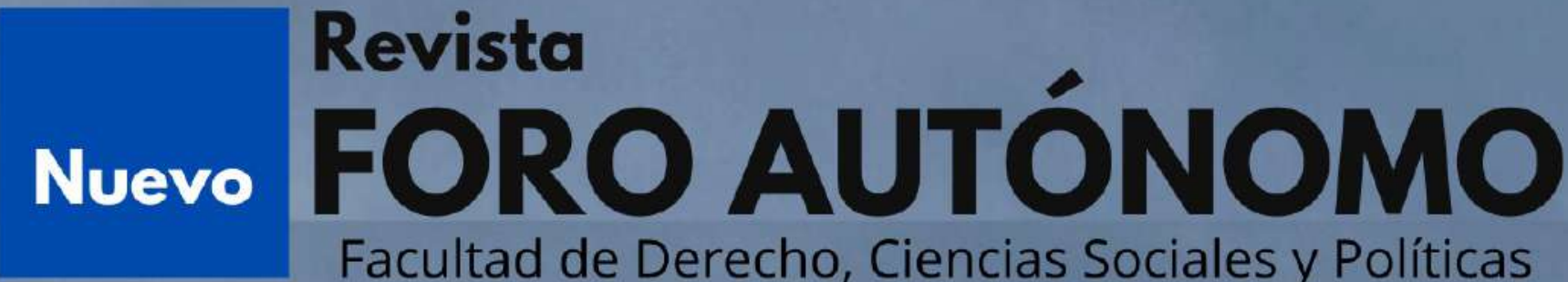

Popayán-Colombia Vol 2, Núm 2 • julio - diciembre de $2021 \quad$ ISSN: 2711- 4856 (En línea) Corporación Universitaria Autónoma del Cauca https://nfa.uniautonoma.edu.co

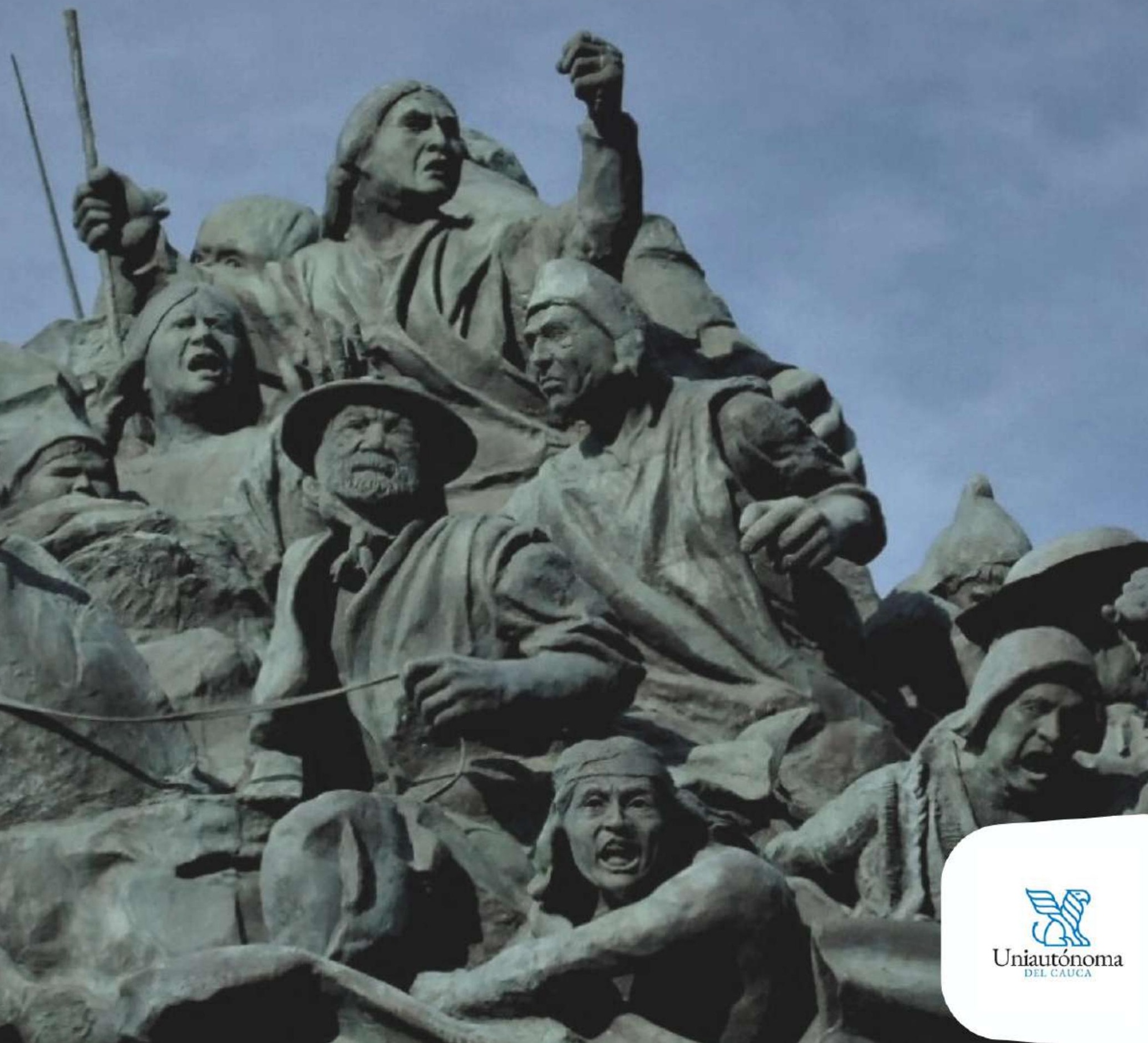





\section{Nuevo FORO RUTÚ, AUOMO}

Volumen 2 - Número 2 • julio-diciembre de 2021 • ISSN: 2711-4856 (en línea)

Corporación Universitaria Autónoma del Cauca

Facultad de Derecho, Ciencias Sociales y Políticas

Sello Editorial Uniautónoma del Cauca

Popayán (Cauca - Colombia)

Correo electrónico: revistaforoautonomo@uniautonoma.edu.co

Website: https://nfa.uniautonoma.edu.co

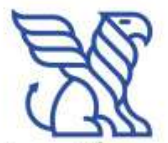

Uniautónoma

Diagramación: Sello Editorial Uniautónoma del Cauca

Foto de portada: Juliana Rodríguez Arango

\section{Comité Científico}

Dra. Lyda Teresa Córdoba Hoyos

Universidad del Valle

Dr. Luis Eduardo Ruano Ibarra

Universidad Cooperativa de Colombia

Dr. Ramsés López Santamaría

Corporación Universitaria Autónoma del Cauca

Dr. Gildardo Vanegas Muñoz

Universidad del Cauca

\section{Comité Editorial Central}

Dr. Daniel Augusto Mantilla Sandoval

Rector Corporación Universitaria Autónoma del Cauca

Dr. Juan Pablo Sterling Casas

Director Revista Nuevo Foro Autónomo

Decano Facultad de Derecho, Ciencias Sociales y Políticas

Mg. William Darío Chará Ordóñez

Editor Revista Nuevo Foro Autónomo 


\section{Contenido}

Las condiciones de posibilidad de Justicia, un análisis

desde la desigualdad social y económica

Julián David Guachetá Torres

La justicia transicional en la Jurisdicción Especial para la Paz

Laura Valentina Barrero Jiménez

Aproximación a los hábitos y técnicas de estudio en instituciones educativas públicas, un estudio de caso en Popayán".

Paola Andrea Gómez Quirós

Empresas transnacionales comosujetos de derecho internacional

35

Victoria Eugenia Paz Trullo

Lucy Esmeralda Paz Trullo

Excepciones y limitaciones del uso de la

fuerza: autonomía universitaria y derecho a la protesta

53

Rubén Darío Chaves Canabal 


\title{
La justicia transicional en la Jurisdicción Especial para la Paz
}

\section{Transitional Justice in the Special Jurisdiction for Peace}

\author{
Laura Valentina Barrero Jiménez* \\ Universidad Militar Nueva Granada \\ correo electrónico: laurabarrerojimenez@gmail.com
}

Recibido: 27/10/2021 • Revisado: 07/11/2021 • Aceptado: 10/12/2021

DOI: https://doi.org/10.46571/NFA.2021.2.2.2

\section{Resumen}

El conflicto armado en Colombia es un fenómeno en el cual han permanecido diversos actores por diferentes motivos y causas, los cuales han superado los cincuenta años. Gracias a la implementación de la justicia transicional a través del Acuerdo de Paz suscrito en el año 2016 incorporado mediante el Sistema Integral de Verdad, Justicia, Reparación y No Repetición, ha permitido que la sociedad atraviese un estado constante de conflicto a la paz, en el cual las víctimas son el eje central de este modelo de justicia. Como principales resultados se identifican el sometimiento de 12.781 colombianos a la justicia especial para la paz, fueron establecidas 6.402 víctimas por ejecuciones extrajudiciales en todo el territorio nacional entre 2002 y 2008, las FARC-EP reconocieron la comisión de delitos como secuestro, se han recibido declaraciones de los máximos lideres de FARC-EP sobre diversos homicidios y la celebración del Acuerdo de Cooperación entre el gobierno nacional y la Corte Penal Internacional.

Palabras clave: Conflicto armado; víctimas: paz; justicia transicional.

\section{Abstract}

The armed conflict in Colombia is a phenomenon in which various actors have remained for different reasons and causes, which have exceeded fifty years. Thanks to the implementation of transitional justice through the Peace Agreement signed in 2016 incorporated through the Comprehensive System of Truth, Justice, Reparation and Non-Repetition, it has allowed society to go through a constant state of conflict to peace, in which the victims are the central axis of this model of justice. The main results include the submission of 12,781 Colombians to the special justice for peace, the establishment of 6,402 victims of extrajudicial executions throughout the national territory between 2002 and 2008, the FARC-EP acknowledged the commission of crimes such as kidnapping, statements have been received from the top leaders of the FARC-EP on various homicides and the conclusion of the Cooperation Agreement between the national government and the International Criminal Court.

keywords: Armed conflict; victims; Peace; transitional justice. 


\section{Introducción}

El conflicto armado interno en Colombia ha sido catalogado como el más antiguo de Latinoamérica, en el cual se encuentran inmersos diversos actores como las fuerzas legítimas del Estado contra aquellos sujetos los cuales no aceptan el orden constitucional.

La historia de la violencia colombiana, está asociada a la brecha económica entre los diferentes sectores de la sociedad y a las divergencias políticas, lo cual ha generado constantes conflictos. No obstante, no existe un consenso para determinar el surgimiento de este fenómeno y en consecuencia han sido múltiples causas y explicaciones que han generado tal efecto.

La justicia transicional contempla mecanismos que viabilizan transición de un Estado de guerra a uno de paz, determinándolo como una decisión de los Estados y no una imposición de un ente internacional, por ende, no tiene carácter coercitivo más allá de la jurisdicción nacional que la instaure, es así que gracias al Acuerdo Final para la Terminación del Conflicto y la Construcción de una Paz Estable y Duradera, suscrito entre el Gobierno Nacional y las FARC-EP se considera como una de las hazañas más importante en la historia colombiana, permitiendo pasar la página a favor de todo un pueblo que anhelaba la paz, por esta razón la justicia y la paz son elementos fundamentales del Estado Social de Derecho, implementados bajo la armonía e integración ciudadana asegurando la convivencia y la vigencia del orden justo mediante el respeto de los derechos humanos.

El punto cinco (5) del Acuerdo celebrado el 24 de noviembre de 2016, se pactó el Sistema Integral de Verdad, Justicia, Reparación y No Repetición, incluyendo la Jurisdicción Especial para la Paz y, el compromiso sobre Derechos Humanos. La implementación de los principios como la verdad, la justicia, la reparación y las garantías de no repetición permite el reconocimiento a las víctimas como el eje central, desarrollándose como sujetos titulares de derechos dentro del proceso que se adelante para establecer responsabilidades de los victimarios y gracias a ello permitirá recuperar la confianza la sociedad civil por parte de las instituciones del Estado.

En virtud del Procedimiento Legislativo Especial para la Paz, el Congreso de Colombia decreto la Ley Estatutaria de la Administración de Justicia en la Jurisdicción Especial para la Paz, Ley 1957 de 2019, el cual corresponde al componente de justicia del Sistema Integral de Verdad, Justicia, Reparación y No Repetición. Esta Alta Corte tiene como función administrar justicia transicional, conocer y juzgar los delitos perpetrados en el marco del conflicto armado con anterioridad al 2016. A la fecha se encuentran siete (7) macrocasos, los cuales representan los hechos más graves del conflicto armado permitiendo evidenciar significativos avances.

\section{Metodología}

Este artículo se estructura bajo el método cualitativo, a partir de la hermenéutica jurídica, para describir el marco normativo concerniente al componente de justicia a víctimas del conflicto armado en Colombia. En especial, se busca describir los precedentes y el marco legal específico sobre el conflicto armado y la justicia transicional implementado a través del 
Acuerdo de Paz suscrito en el año 2016, partiendo del análisis y estructura del Sistema Integral de Verdad, Justicia, Reparación y No Repetición (SIVJRNR), que conllevaron a la creación de la Jurisdicción Especial para la Paz como aquella Alta Corte encargada de investigar, esclarecer, y administrar justicia transicional sobre los crímenes más graves perpetrados con anterioridad al 2016.

\section{Resultados}

\section{Sistema de Verdad, Justicia, Reparación y No Repetición}

En desarrollo de la Mesa de Diálogos de la Habana, el 6 de agosto de 2014 se conformó la Comisión Historia del Conflicto y sus Víctimas a cuyos integrantes se les asigno la labor de "producir un informe sobre los orígenes y las múltiples causas del conflicto, los principales factores y condiciones que han facilitado o contribuido a su persistencia, y los efectos e impactos más notorios del mismo sobre la población" (Comisión Historia del Conflicto y sus Víctimas, [CHCV], 2015). A pesar de exponer una serie de teorías sobre ello, se determinó que cada actor, en cada momento histórico del conflicto ha defendido ideas y justificaciones para ingresar o permanecer dentro del mismo, por lo cual, se ha considerado que es heterogéneo en sus componentes.

Mediante el artículo 22 de la Constitución Política, se consagra la paz como un derecho y un deber de obligatorio cumplimiento, por esta razón es que a través del Estado se puede garantizar el cumplimiento de los fines esenciales para el cual fue instituido. Por ello, los conflictos expresan la inestabilidad social y política, así como la inseguridad jurídica que se genera en la adopción de normas según la convivencia o el interés de mantener condiciones, que en general reproducen causas de la violencia y son detonantes de nuevos ciclos de conflicto, efectuándose de forma más violenta en contra de la sociedad civil.

En diferentes gobiernos del país de forma continua han pretendido e intentado buscar negociar y encontrar una salida concretada entre los contendientes para dar fin al conflicto armado, sin embargo, se ha evidenciado históricamente la complejidad en el curso de las negociaciones, así como la implementación de los pactos. El gobierno de Juan Manuel Santos continuo con el deseo de terminar el conflicto y establecer la paz, motivo por el cual se iniciaron los Diálogos de la Habana (Cuba), entre el Gobierno Nacional y las Fuerzas Armadas Revolucionarias de Colombia - Ejército del Pueblo (FARC-EP), con la intervención de la comunidad internacional, los cuales concluyeron en el "Acuerdo Final para la Terminación del Conflicto y la Construcción de una Paz Estable y Duradera" suscrito el día 24 de noviembre 2016, considerándose el hito histórico en el marco del conflicto y la búsqueda de la paz.

El Acuerdo Final para la Terminación del Conflicto y la Construcción de una Paz Estable y Duradera, firmado entre el Gobierno Nacional y las FARC-EP crea e incorpora en la Constitución Política de Colombia mediante el Acto Legislativo 01 de 2017 el Sistema Integral de Verdad, Justicia, Reparación y No Repetición (SIVJRNR), el cual es un conjunto de mecanismos que busca centralizar a las víctimas del conflicto armado interno, garantizando todos sus derechos por medio de la implementación de medidas restaurativas y reparadoras. 
Este Sistema está compuesto por mecanismos como la Comisión para el Esclarecimiento de la Verdad, la Convivencia y la No Repetición (CEV), la Jurisdicción Especial para la Paz (JEP) y la Unidad de Búsqueda de Personas dadas por Desaparecidas en el Contexto y en Razón del Conflicto Armado (UBPD).

\section{La Jurisdicción Especial para la Paz}

La Jurisdicción Especial para la Paz es el componente de justicia de carácter transicional, la cual no es una forma especial de justicia, sino una justicia adaptada a sociedades. Este es el conjunto de medidas que se ha implementado en los periodos de transición que viven los Estados, bien sea en un dictadura a la democracia o de una guerra a la paz, mediante "una serie de mecanismos o procesos dirigidos a lograr un equilibrio entre el imperativo jurídico de justicia para las víctimas y la necesidad política de paz" (Uprimny y Saffon, 2008 p. 166) con el objetivo de dar solución a las graves violaciones a los derechos humanos, los crímenes de guerra y los crímenes de lesa humanidad cometidos en el conflicto armado colombiano.

La Alta Corte dio apertura a sus instalaciones el 15 de marzo de 2018, dando ejercicio a su competencia de carácter temporal, personal y material, toda vez que su función es investigar, esclarecer, y administrar justicia transicional sancionando los crímenes más graves ocurridos en Colombia con anterioridad al 1 de diciembre de 2016, garantizando a las víctimas el derecho a la verdad, la justicia, la reparación y la no repetición mediante iniciativas de paz, reconciliación y democracia. Por tratarse de un mecanismo transitorio es importante destacar que su funcionamiento y existencia no podrá ser superior a veinte (20) años.

La Jurisdicción Especial para la Paz incorpora prácticas de la justicia restaurativa bajo la participación y el fundamento que, entre la víctima, el victimario y la sociedad sean solucionados los hechos que afectaron el tejido social y se construya un acuerdo de indemnización o reparación (material o inmaterial), en el cual, la primera sienta que ha sido debidamente reparada y el victimario que al hacerlo y encontrar su perdón ha reparado el daño causado, lo cual constituye la base del proceso de reconciliación y reintegración a la sociedad de quien se había apartado de ella. Sin embargo, la -JEP no cuenta con precedente alguno, por ello funciona bajo una naturaleza mixta entre la justicia punitiva y restaurativa.

Quienes pueden comparecen ante esta Alta Corte son (i) los excombatientes de las FARC-EP, (ii) integrantes de la fuerza pública que hayan sido procesados o cometido delitos relacionado con el conflicto armado, (iii) terceros los cuales son clasificados como agentes del Estado que no hayan sido parte de la fuerza pública o civiles que hayan sido procesados o cometido delitos relacionados con el conflicto armado (la participación es de carácter voluntaria) y (iv) personas implicadas en conductas cometidas en contextos de protesta social o disturbios internos.

La Jurisdicción Especial para la Paz está constituida por tres (3) Salas, (Sala de Reconocimiento de Verdad, de Responsabilidad y de Determinación de los Hechos y Conductas, Sala de Amnistía o Indulto y la Sala de Definición de Situaciones Jurídicas), un Tribunal de Paz el cual está conformado por cinco (5) secciones (Sección de Reconocimiento de Verdad y de Responsabilidad de los Hechos y Conductas, Sección de Ausencia de 
Reconocimiento de Verdad y de Responsabilidad de los Hechos y Conductas, Sección de Revisión de Sentencias, la Sección de Apelación y la Sección de Estabilidad y Eficiencia), la Unidad de Investigación y Acusación -UIA y la Secretaria Ejecutiva.

Las considerables cifras de los hechos perpetrados en el marco del conflicto armado permiten fundamentar que esta Jurisdicción durante el término de permanencia no podrá investigar todos los casos. Es por ello, que se deben seleccionar los más graves y representativos mediante los criterios de selección y priorización establecidos por la Sala de Reconocimiento, en donde la -JEP determinará cómo serán reparadas las víctimas y qué tipo de sanción recibirán los comparecientes, por esta razón, actualmente se encuentran vigentes siete (7) casos.

De acuerdo a los informes estadísticos de la Jurisdicción Especial Para la Paz (2020), hasta dicha fecha 12.234 colombianos se han sometido a la justicia especial para la paz, logrando avances como (i) establecer que aproximadamente "6.402 personas fueron muertas ilegítimamente para ser presentadas como bajas en combate en todo el territorio nacional entre 2002 y 2008" (Jurisdicción Especial para la Paz, [JEP], 2021, párr. 1);; (ii) se han encontrado e identificado decenas de desaparecidos en todo el país; (iii) las FARC-EP reconocieron la comisión de secuestros; (iv) se escuchó a los máximos responsables del reclutamiento de miles de niños y niñas en el conflicto; y (v) se recibió la declaración de los máximos líderes de las FARC-EP sobre los homicidios de Álvaro Gómez, Pablo Guarín, Hernando Pizarro, el general Fernando Landazábal, Jesús Antonio Bejarano y José Fedor Rey.

\section{La Corte Penal Internacional}

La Corte Penal Internacional desde el año 2004 dio apertura a un examen preliminar sobre los crímenes de guerra y lesa humanidad consumados en el marco del conflicto armado colombiano dada la sospecha de que no fuesen juzgados de manera íntegra, por ello durante la visita del fiscal Karimk Khan fue "demostrada capacidad y voluntad de Colombia hasta la fecha para administrar genuinamente justicia relacionada con los crímenes de competencia de la Corte Penal Internacional" (Acuerdo de Cooperación entre el gobierno de Colombia y la oficina del fiscal de la Corte Penal Internacional, 2021 p. 2). Toda vez que fue confirmada la efectiva implementación del Sistema Integral de Verdad, Justicia, Reparación y No Repetición.

El pasado 28 de octubre de 2021 se celebró el Acuerdo de Cooperación entre el gobierno nacional y la Corte Penal Internacional, determinando que el Estado colombiano se comprometió a (i) continuar "apoyando los procesos pertinentes ante las diferentes instancias judiciales interconectadas, incluyendo la justicia ordinaria, el sistema de Justicia y Paz y la Jurisdicción Especial para la Paz, en cumplimiento de los marcos procesales temporales previstos para las mismas" (ídem); (ii) promover la cooperación entre entidades del Estado como la Fiscalía General de la Nación y la Jurisdicción Especial para la Paz; (iii) programar visitas anuales entre la fiscalía de la Corte Penal Internacional y las instituciones judiciales nacionales; y (iv) la Fiscalía del órgano internacional podrá nuevamente intervenir ante toda medida que pretenda obstaculizar el proceso, funcionamiento, imposición de sanciones, y otras establecidas según el Acuerdo de Paz. 


\section{Conclusiones}

En el conflicto armado se encuentran involucrados diversos actores que tiene como por objeto intereses personales nada legítimos bajo la perspectiva nacional e internacional, sin embargo, no existe un conceso que define o determine el nacimiento del conflicto armado en Colombia.

La justicia transicional tiene como finalidad recuperar la confianza de la sociedad civil en las instituciones del Estado, más cuando éste debe garantizar que no se reiteren esta serie de actuaciones atroces consumadas en el conflicto armado, no obstante, se ha demostrado que la Jurisdicción Especial para la Paz ha obtenido avances significativos reconocidos por la Corte Penal Internacional y otros Estados. Si bien es cierto no se trata de una transición sencilla, pero vale la pena hacer todo lo posible por dejar atrás un Estado de constante guerra y transformarlo en un trabajo constante por alcanzar la paz.

\section{Referencias Bibliográficas}

Comisión Histórica del Conflicto y sus Víctimas. (inf.téc.) (2015). Versión final de informes: Contribución al entendimiento del conflicto armado en Colombia. Recuperado de http://www.humanas.unal.edu.co/observapazyconflicto/files/5714/6911/9376/Versio n_final_informes_CHCV.pdf

Congreso de Colombia. (6 de junio de 2019) Artículo 84 [Título V]. Ley Estatutaria de la Administración de Justicia en la Jurisdicción Especial para la Paz. [Ley 1957 de 2019]. DO: 50.976 .

Corte Penal Internacional. (28 de octubre de 2021) Acuerdo de Cooperación entre el gobierno de Colombia y la oficina del fiscal de la Corte Penal Internacional. Recuperado de https://www.icc-cpi.int/itemsDocuments/20211028-OTP-COL-CooperationAgreement-SPA.pdf

Jurisdicción Especial para la Paz. (s.f.) ¿Qué es la JEP?: Misión, visión y objetivos. Recuperado de https://www.jep.gov.co/JEP/Paginas/Mision-vision-objetivos.aspx

Jurisdicción Especial para la Paz. (2021) Prensa: La JEP hace pública la estrategia de priorización dentro del Caso 03, conocido como el de falsos positivos. Recuperado de https://www.jep.gov.co/Sala-de-Prensa/Paginas/La-JEP-hace-p\%C3\%BAblica-laestrategia-de-priorizaci\%C3\%B3n-dentro-del-Caso-03,-conocido-como-el-de-falsospositivos.aspx

Jurisdicción Especial para la Paz. (2020). Informe Estadístico. (núm. 1), [p. 28]. Recuperado de https://www.jep.gov.co/rendiciondecuentas/Informes\%202020/Informe\%20Estadi\% CC\%81stico.pdf

Uprimny, R., y Saffon, M. (2008). Usos y Abusos de la Justicia Transicional en Colombia. Anuario de Derechos Humanos. (Vol. 4), [p. 166]. Doi:10.5354/0718-2279.2011.13511. 